\title{
Galeterone for the treatment of advanced prostate cancer: the evidence to date
}

\author{
This article was published in the following Dove Press journal: \\ Drug Design, Development and Therapy \\ 15 July 2016 \\ Number of times this article has been viewed
}

\author{
Diogo A Bastos' \\ Emmanuel S Antonarakis ${ }^{2}$ \\ 'Department of Oncology, \\ Hospital Sirio-Libanes, Sao Paulo, \\ Brazil; 'Department of Oncology \\ and Urology, Sidney Kimmel \\ Comprehensive Cancer Center, \\ Johns Hopkins University School of \\ Medicine, Baltimore, MD, USA
}

\begin{abstract}
Major advances have been achieved recently in the treatment of metastatic castrationresistant prostate cancer, resulting in significant improvements in quality of life and survival with the use of several new agents, including the next-generation androgen receptor (AR)-targeted drugs abiraterone and enzalutamide. However, virtually all patients will eventually progress on these therapies and most will ultimately die of treatment-refractory metastatic disease. Recently, several mechanisms of resistance to AR-directed therapies have been uncovered, including the AR splice variant 7 (AR-V7), which is a ligand-independent constitutionally-active form of the AR that has been associated with poor outcomes to abiraterone and enzalutamide. Galeterone, a potent anti-androgen with three modes of action (CYP17 lyase inhibition, AR antagonism, and AR degradation), is a novel agent under clinical development that could potentially target both full-length AR and aberrant AR, including AR-V7. In this manuscript, we will first discuss the biological mechanisms of action of galeterone and then review the safety and efficacy data from Phase I and II clinical studies of galeterone in patients with metastatic castration-resistant prostate cancer. A Phase III study of galeterone (compared against enzalutamide) in AR-V7positive patients is currently underway, and represents the first pivotal trial using a biomarkerselection design in this disease.
\end{abstract}

Keywords: galeterone, AR splice variants, AR-V7, castration-resistant prostate cancer

\section{Introduction}

Despite significant recent advances in the treatment of advanced prostate cancer, most patients with metastatic spread will ultimately die of progressive disease, and prostate cancer remains one of the leading causes of cancer-related deaths in men worldwide. ${ }^{1,2}$

Over the last decade, there has been an increasing understanding of mechanisms of disease progression after androgen deprivation therapy, which has led to the development of multiple new androgen receptor (AR)-directed drugs with promising activity for patients with metastatic castration-resistant prostate cancer (mCRPC). ${ }^{3-5}$ Of those, abiraterone (an oral CYP17 inhibitor), and enzalutamide (an oral AR-antagonist), have demonstrated significant clinical activity and have been approved by the US Food and Drug Administration (FDA) and the European Medicines Agency (EMA) based on notable improvements in median overall survival (OS), radiographic progression-free survival (rPFS), and quality of life. ${ }^{6,7}$ Nonetheless, these trials also demonstrate that about $10 \%$ to $20 \%$ of all patients with mCRPC show primary resistance to abiraterone or enzalutamide, and most of the remaining patients who have an initial clinical benefit will eventually develop disease progression later. ${ }^{8-11}$ Since patients progressing on abiraterone or enzalutamide often present with a rising PSA, it has become evident that many resistance mechanisms are related to persistent androgen/AR
Correspondence: Emmanuel S Antonarakis

Sidney Kimmel Comprehensive Cancer Center, Johns Hopkins University School of Medicine, 1650 Orleans St, CRBI-IM45, Baltimore, MD, USA Email eantonal@jhmi.edu 
signaling, including AR and CYP17 upregulation, activating AR mutations, AR splice variants, glucocorticoid-receptor upregulation, and others. ${ }^{12-20}$

Among these, AR splicing variants have received a lot of attention recently. In particular, AR splice variant 7 (AR-V7) is a constitutionally-active variant of the AR that lacks the ligand-binding domain (LBD) and has emerged as an important mechanism of primary and acquired resistance to AR-targeted agents targeting the LBD of the AR. ${ }^{18,21}$ One potentially promising strategy would be to identify agents that could overcome this resistance mechanism by inhibiting the AR outside of the androgen-binding site. In this manuscript, we will review the preclinical and clinical data related to galeterone, a multi-targeted AR-signaling inhibitor for the treatment of CRPC.

\section{Overview of approved agents for CRPC}

Over the last decade, a major paradigm shift has been observed in the treatment of mCRPC, with approval of several new agents with different mechanisms of action, including cytotoxic chemotherapy (cabazitaxel) after docetaxel failure, ${ }^{22,23}$ next-generation AR-directed therapies (abiraterone and enzalutamide), ${ }^{8-11,24,25}$ an autologous immunotherapy agent (sipuleucel-T), ${ }^{26}$ and the $\alpha$-emitting radiopharmaceutical radium-223. ${ }^{27}$ All of these approved agents have demonstrated significant clinical activity with OS improvement and benefits in several secondary endpoints included in each trial (Table 1). In daily medical practice, these agents continue to provide clinically meaningful benefits including pain relief and improvements in quality of life. The major challenge that clinicians face when treating patients with mCRPC is how to best sequence these agents in order to maximize benefits for an individual patient. ${ }^{28-30}$ Currently, oncologists often use clinical parameters such as pathology, symptoms, volume and location of metastasis, and proportion of PSA level to disease volume to help define the most appropriate agent to be used, since there are no predictive biomarkers to date that help in selecting the best treatment strategy. ${ }^{29}$ Many trials are currently underway evaluating different treatment sequences as well as various drug combinations in order to maximize outcomes. ${ }^{30}$ Hopefully in the future, with a better understanding of the mechanisms of drug resistance and response, predictive biomarkers will be identified to determine the use of agents most likely to benefit each patient (ie, treatment-selection biomarkers).

\section{Mechanisms of resistance to AR-directed therapies}

Despite the significant success achieved with the nextgeneration AR-directed therapies, eventually all patients will progress despite these therapies and will ultimately die of progressive metastatic disease. Therefore, it is key to uncover these mechanisms to allow the development of newer and more active agents, which could overcome the known resistance mechanisms. In addition, this could aid in the development of predictive biomarkers that could aid in treatment selection choices. Several mechanisms of resistance to AR-directed therapies have been described, and broadly divided into 1) AR-dependent mechanisms and 2) AR-independent mechanisms.

\section{AR-dependent mechanisms of resistance}

The main AR-dependent mechanisms of therapeutic resistance include CYP17 and AR upregulation, AR splice variants, activating AR mutations, and GR upregulation

Table I Phase III clinical trials of FDA-approved drugs for metastatic castration-resistant prostate cancer

\begin{tabular}{|c|c|c|c|c|c|c|c|c|c|c|}
\hline \multirow[t]{2}{*}{ Study } & \multirow[t]{2}{*}{ Year } & \multirow[t]{2}{*}{ Indication } & \multirow[t]{2}{*}{$\mathbf{N}$} & \multirow{2}{*}{$\begin{array}{l}\text { PSA }_{50} \\
\text { decline }^{a}\end{array}$} & \multirow{2}{*}{$\begin{array}{l}\text { SRE } \\
\text { benefit }\end{array}$} & \multirow{2}{*}{$\begin{array}{l}\text { Quality } \\
\text { of life }\end{array}$} & \multirow{2}{*}{$\begin{array}{l}\text { mPFS } \\
\text { (months) }\end{array}$} & \multicolumn{3}{|c|}{ Overall survival } \\
\hline & & & & & & & & $\begin{array}{l}\text { Median } \\
\text { (months) }\end{array}$ & HR & $P$-value \\
\hline Docetaxel vs mitoxantrone $e^{\mathrm{b}, 23}$ & 2004 & Ist line chemo & 1,006 & $45 \%$ vs $32 \%$ & NA & Yes & NS & 18.9 vs 16.5 & 0.76 & 0.009 \\
\hline Cabazitaxel vs mitoxantrone $\mathrm{e}^{\mathrm{b}, 22}$ & 2010 & Post-docetaxel & 755 & $39 \%$ vs $18 \%$ & NA & NA & 2.8 vs 1.4 & 15.1 vs 12.7 & 0.70 & $<0.00$ I \\
\hline Sipuleucel-T vs placebo ${ }^{26}$ & 2010 & Pre- and post-docetaxel & 512 & $2.6 \%$ vs $1.3 \%$ & NA & NA & 3.7 vs 3.6 & 25.8 vs 21.7 & 0.78 & 0.03 \\
\hline Abiraterone vs placebo 8,24 & 2011 & Post-docetaxel & 1,195 & $29 \%$ vs $6 \%$ & Yes & Yes & 5.6 vs 3.6 & 14.8 vs 10.9 & 0.65 & $<0.001$ \\
\hline Abiraterone vs placebo 9,25 & 2012 & Pre-docetaxel & 1,088 & $62 \%$ vs $24 \%$ & NA & Yes & 16.5 vs 8.3 & 34.7 vs 30.3 & 0.81 & 0.0033 \\
\hline Enzalutamide vs placebo ${ }^{10}$ & 2012 & Post-docetaxel & 1,199 & $54 \%$ vs $2 \%$ & Yes & Yes & 8.3 vs $2.9^{c}$ & 18.4 vs 13.6 & 0.63 & $<0.001$ \\
\hline Radium-223 vs placebo ${ }^{27, d}$ & 2013 & Pre- and post-docetaxel ${ }^{e}$ & 921 & $16 \%$ vs $6 \%$ & Yes & Yes & 3.6 vs $3.4^{g}$ & 14.9 vs $\mid 1.3$ & 0.70 & $<0.001$ \\
\hline Enzalutamide vs placebo" & 2014 & Pre-docetaxel & 1,717 & $78 \%$ vs $3 \%$ & Yes & Yes & NR vs $3.9^{\circ}$ & NR vs 31.0 & 0.73 & $<0.001$ \\
\hline
\end{tabular}

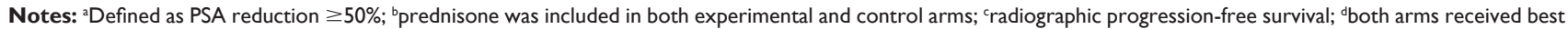

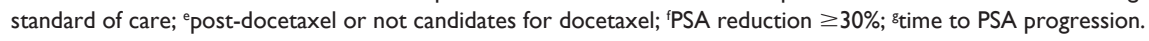

Abbreviations: N, number of patients; SRE, skeletal related events; mPFS, median progression-free survival; chemo, chemotherapy; NS, non-significant; NA, not assessed; NR, not reached; PSA, prostate specific antigen; FDA, US Food and Drug Administration; HR, hazard ratio. 
(ie, bypass pathways). ${ }^{20,31}$ Ultimately, these mechanisms will allow AR nuclear translocation and activation of nuclear transcriptional programs, or activation of androgen-response elements by alternative steroid receptors, leading to proliferation and disease progression despite testosterone-depleting agents (eg, androgen deprivation, abiraterone) or AR antagonists (eg, enzalutamide, apalutamide).

The role of CYP17 and AR overexpression was demonstrated by three studies with similar designs conducted by Efstathiou et al. In these studies, patients treated with abiraterone, ${ }^{12}$ enzalutamide,,$^{13}$ or both ${ }^{32}$ underwent transiliac bone marrow biopsies: AR and CYP17 expression was assessed by immunohistochemistry. A pre-treatment androgen-signaling signature was proposed based on CYP17 expression $([+],>10 \%)$ and AR $\mathrm{N}$-terminal domain expression $([+++],>75 \%)$, which predicted benefit with ARdirected therapies in these studies. Moreover, in two of these studies, the presence of AR-V7 was assessed by immunohistochemistry at baseline, and was associated with primary resistance to enzalutamide ${ }^{13}$ or the combination of abiraterone and enzalutamide. ${ }^{32}$

One potential predictive biomarker for resistance to the currently approved AR-directed therapies is the AR splice variants, particularly AR-V7, which is a constitutionally active form of the AR that lacks the LBD, the target of enzalutamide and abiraterone. Amongst the AR splice variants (22 have been described to date), ${ }^{33} \mathrm{AR}-\mathrm{V} 7$ is the most prevalent and its expression increases about 20-fold in the setting of AR-full length (FL) suppression by castration, suggesting that AR-V7 is biologically important and may be associated with ligand-independent AR-dependent progression of disease. . $^{17,34}$ The clinical importance of AR-V7 in the setting of treatment with AR-directed agents was demonstrated in a recent pilot study of patients with $\mathrm{MCRPC}$ treated with abiraterone or enzalutamide. ${ }^{18}$ In this prospective study, AR-V7 status was determined by a circulating tumor cell (CTC)-based real-time polymerase chain reaction (RT-PCR) assay in 62 patients and was associated with clinical outcomes for abiraterone $(\mathrm{n}=31)$ or enzalutamide $(\mathrm{n}=31)$. In both cohorts, the rate of PSA decline $\geq 50 \%\left(\mathrm{PSA}_{50}\right)$ was high in the AR-V7 negative patients $(52.6 \%$ and $68 \%$ for enzalutamide and abiraterone, respectively), but no AR-V7-positive patients achieved a $\mathrm{PSA}_{50}$ response. Moreover, in both cohorts, the AR-V7negative group demonstrated a significantly higher diseasefree survival and OS..$^{18}$ Although these results are preliminary and need to be validated in larger prospective studies, ${ }^{35}$ the preclinical rationale and the magnitude of results observed strongly suggest that patients with AR-V7-positive CTCs may show primary resistance to abiraterone and enzalutamide. In addition, the CTC-based assay for AR-V7 detection requires further biomarker validation before incorporation into clinical practice. ${ }^{36}$ One notable finding is that the AR-V7 status was not associated with resistance to taxane-based chemotherapy in recent studies, ${ }^{37,38}$ highlighting the importance of this biomarker for future treatment selection for patients with CRPC if these results are confirmed. Preliminary data on patients with serial "liquid biopsies" for CTC-based AR-V7 analysis suggest that some patients develop AR-V7 CTCs upon disease progression and in some patients the AR-V7 status may be converted from positive to negative when treated with taxane-based chemotherapy. ${ }^{39}$ The clinical significance of this remains unknown.

AR point mutations are another mechanism of resistance increasingly being described, particularly in the setting of acquired resistance to abiraterone and next-generation AR antagonists (enzalutamide and apalutamide). ${ }^{40}$ The AR mutations described may convert these AR-antagonists into pure agonists (AR F877L), ${ }^{15,16}$ or may allow the AR to be activated by progesterone (AR T878A) or glucocorticoids (AR L702H) in abiraterone/prednisone-treated patients. ${ }^{14,41,42}$ These studies have shown that the presence of these activating mutations in AR are associated with inferior PFS and OS outcomes compared to men that harbor neither mutated nor amplified AR.

Therefore, targeting the AR-V7 and activating AR mutations is an area of priority for development of novel therapies to overcome resistance to drugs targeting the LBD of the AR, such as abiraterone, enzalutamide, and even newer drugs currently being tested in clinical trials such as apalutamide (ARN-509) and ODM-201. Some of these resistance mechanisms may perhaps be overcome with the use of galeterone, which has the ability to degrade various forms of the AR at the protein level.

\section{AR-independent mechanisms of resistance}

The AR-independent mechanisms of resistance have been increasingly recognized over the past few years due to a significant proportion of patients progressing after more active AR-directed drugs such as abiraterone and enzalutamide, often with a very aggressive clinical phenotype, described as anaplastic/small cell variant, characterized by a low PSA, osteolytic bone metastasis, visceral disease, refractoriness to available therapies, and short survival. ${ }^{43}$ In addition, intermediate phenotypes (such as the recently coined histology: intermediate atypical carcinoma) ${ }^{44}$ can 
be recognized in patients progressing after multiple lines of hormonal therapy. These patients often develop ARindependent mechanisms of resistance, including activation of PI3K/AKT pathway (often resulting from PTEN loss), Rb loss, inactivating TP53 mutations, expression of AURKA and N-Myc, alteration in DNA-repair genes, among others. Currently, several strategies are being developed to target these alterations and more comprehensive reviews on this topic can be found elsewhere. ${ }^{45-48}$

\section{Galeterone: evidence to date Preclinical studies}

During the effort to identify potent CYP17 inhibitors in the 1990s and 2000s, 3 3 -(hydroxy)-17-(1H-benzimidazole-1-yl) androstane-5,16-dione (galeterone, formerly TOK-001 or VN/124-1) was identified as a multi-targeted AR inhibitor candidate. Initially identified as a potent CYP17 inhibitor, multiple subsequent preclinical studies have demonstrated that galeterone also acts as an AR antagonist to both FL and mutant AR, in addition to its ability to degrade the AR, including AR splice variants (Figure 1). ${ }^{49-54}$ It has also been demonstrated that galeterone inhibits enzalutamide-resistant cells in vitro, and also blocks AR nuclear translocation and activation of androgen-dependent genes such as PSA and TMPRSS2. ${ }^{55}$ The discovery, chemical properties and preclinical development of galeterone have been comprehensively reviewed elsewhere, ${ }^{56}$ although the current understanding of its degradation of AR will be reviewed briefly here.

\section{AR degradation}

One of the described mechanisms of AR regulation involves the E3 ubiquitin ligase pathway. ${ }^{57,58}$ It has been described that the AR, MDM2, and AKT form a complex in vivo that results in ubiquitination and proteasome degradation of the AR. Specifically, it is thought that AKT phosphorylates MDM2 and the AR itself leading to MDM2 binding to the $\mathrm{AR}$ as a required step for AR degradation, and it has been shown that specific MDM2 binding site mutations inhibit

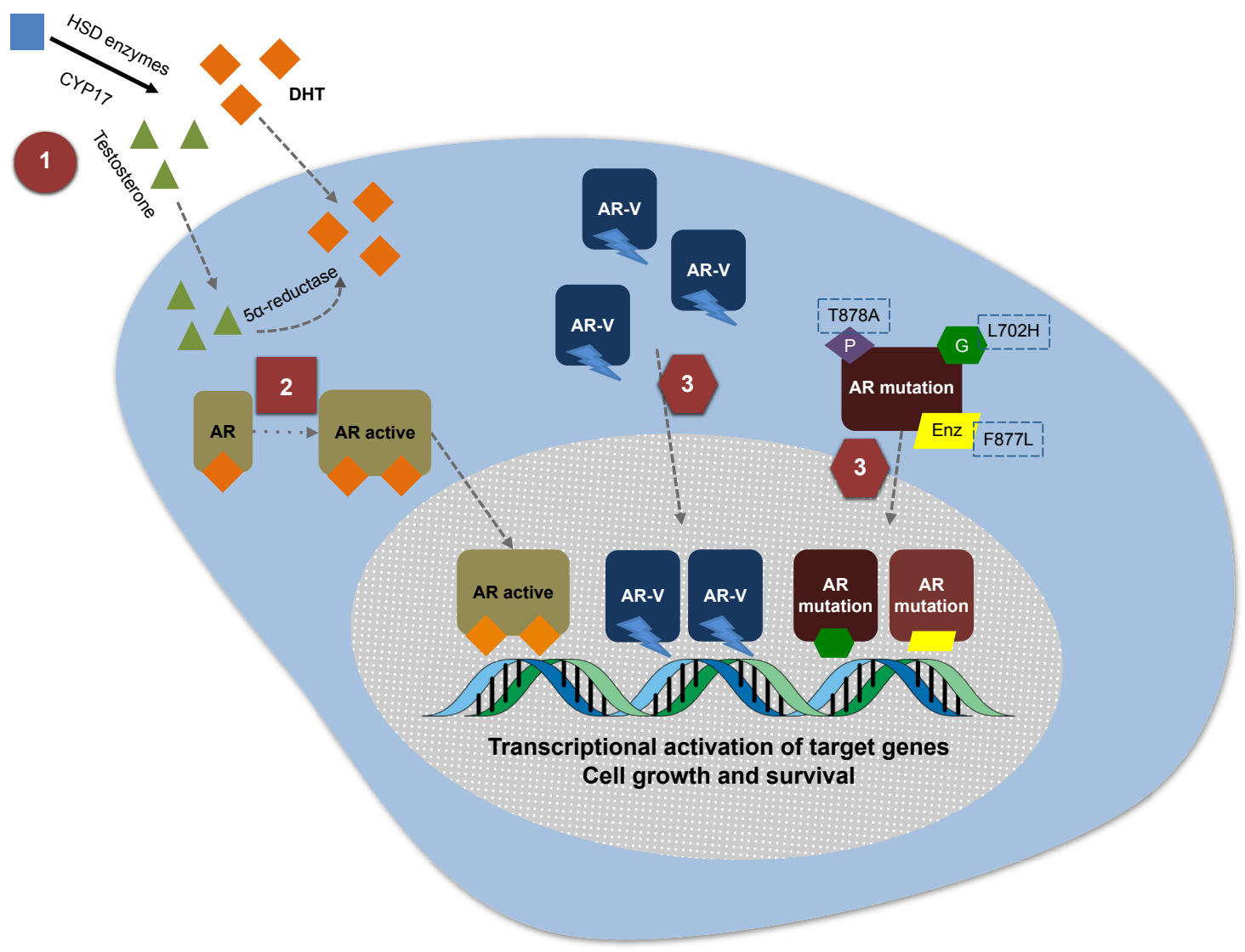

Figure I Three mechanisms of action of galeterone.

Notes: This figure highlights the androgen receptor (AR) activation axis, with conversion of testosterone to dihydrotestosterone (DHT) by the $5 \alpha-$-reductase enzyme, and subsequent AR activation, dimerization, nuclear translocation and activation of transcriptional activation of target genes. The figure also demonstrates potential mechanisms of resistance to AR therapies, including the development of $A R$ splice variants (AR-V) and AR mutations. Finally, it highlights galeterone's mechanisms of action in each of these AR signaling pathways implicated in resistance to novel androgen/AR-directed therapies: I) CYP lyase inhibition; 2) AR antagonism to both full-length and mutant AR; and 3) degradation of the AR, including AR splice variants.

Abbreviation: Enz, enzalutamide. 
AR ubiquitination and degradation..$^{59,60}$ In addition, other E3 ubiquitin ligases are probably involved in the AR regulation process, such as $\mathrm{CHIP}^{61}$ and SKP2 ${ }^{62}$ which also promote AR degradation, and Siah2, ${ }^{63} \mathrm{RNF} 6,{ }^{64}$ and USP $12{ }^{65,66}$ which promote deubiquitination and AR activation. ${ }^{57}$ To this end, it has been shown that galeterone-induced AR degradation is blocked by co-administration of proteasome inhibitors and also by E3 ligases MDM2 and CHIP selective knockdown, suggesting that galeterone disrupts the AR through proteasome degradation. ${ }^{67}$ Notably, a recent study that screened a panel with 22 deubiquitinating enzymes in vitro showed that galeterone inhibits the enzymatic activity of USP12 and also binds directly to the USP12 and USP12/UAF1 complexes, which dephosphorylate AKT ${ }^{68}$ Therefore, the summation of data suggests that galeterone induces AR proteasomal degradation through the E3 ubiquitin ligase pathway, by changing the balance between ubiquitination and deubiquitination, both with respect to the FL AR and AR splice variants. ${ }^{67,68}$

\section{Clinical studies:ARMORI and ARMOR2}

The Androgen Receptor Modulation Optimized for Response (ARMOR) Phase I and Phase II studies conducted with galeterone were recently published and demonstrated that galeterone is a well tolerated drug with promising clinical activity for patients with CRPC. ${ }^{69}$ Table 2 summarizes the main characteristics and outcomes of the ARMOR trials.

The Phase I ARMOR1 trial included 49 patients with progressive CRPC, including patients with metastatic $\left(\mathrm{M}_{1}\right)$ and non-metastatic $\left(\mathrm{M}_{0}\right)$ disease, and excluded patients who

Table 2 Main characteristics and outcomes of the ARMORI and ARMOR2 clinical trials

\begin{tabular}{|c|c|c|c|}
\hline & ARMORI ${ }^{69}$ & $\begin{array}{l}\text { ARMOR2, } \\
\text { part I }\end{array}$ & $\begin{array}{l}\text { ARMOR2, parts I } \\
\text { and } 2 \text { (combined } \\
\text { study) }\end{array}$ \\
\hline Number of patients & 49 & 28 & 107 \\
\hline Metastatic disease $\left(M_{1}\right)$ & $51 \%$ & $86 \%$ & $77 \%$ \\
\hline $\begin{array}{l}\text { Abi-R or Enz-R } \\
\text { patients }\end{array}$ & No & $\begin{array}{l}\text { Abi-R: three } \\
\text { patients }\end{array}$ & $\begin{array}{l}\text { Abi-R: } 37 \text { patients } \\
\text { Enz-R: nine patients }\end{array}$ \\
\hline Drug formulation & Capsules & SDD tablets & SDD tablets \\
\hline Food effect & Yes & No & No \\
\hline Dose range & $\begin{array}{l}650 \mathrm{mg} \\
975 \mathrm{mg} \\
\mathrm{I}, 300 \mathrm{mg} \\
\mathrm{I}, 950 \mathrm{mg} \\
2,600 \mathrm{mg}\end{array}$ & $\begin{array}{l}\mathrm{I}, 700 \mathrm{mg} \\
2,550 \mathrm{mg} \\
3,400 \mathrm{mg}\end{array}$ & $2,550 \mathrm{mg}$ \\
\hline PSA decline $\geq 30 \%$ & $49 \%$ & $64 \%$ & $83 \%^{a}$ \\
\hline $\mathrm{PSA}_{50}$ & $22.4 \%$ & $48 \%$ & $70 \%^{\mathrm{a}}$ \\
\hline
\end{tabular}

Note: aPSA decline results in the $M_{0}$ and $M_{1}$ treatment-naïve cohorts.

Abbreviations: Abi-R, abiraterone refractory; Enz-R, enzalutamide refractory; SDD, spray dry dispersion; PSA $_{50}$, PSA decline $\geq 50 \%$. had previously received taxane chemotherapy, ketoconazole, abiraterone, or enzalutamide. This was a multicenter, doseescalation study, which included eight dose-cohorts to assess the tolerability, safety, and efficacy of oral galeterone capsules (micronized powder, $325 \mathrm{mg}$ ), with dose-levels ranging from $650 \mathrm{mg}$ to $2,600 \mathrm{mg}$ daily. After a healthy volunteer study demonstrated a significant food effect with the capsule formulation used in the ARMOR1 study, a new formulation with no food effect - the galeterone spray dry dispersion (SDD) - was developed and was included in the dose-escalation component of the Phase II trial of galeterone in CRPC (ARMOR2, part 1). This Phase II study included 28 patients in three dosing cohorts using the $425 \mathrm{mg}$ SDD tablets $(1,700 \mathrm{mg}, 2,550 \mathrm{mg}$ and 3,400 $\mathrm{mg}$ daily) and allowed inclusion of abiraterone-resistant patients. Results of the healthy volunteer study also demonstrated equivalent serum concentrations using either $2,600 \mathrm{mg}$ capsules or $1,700 \mathrm{mg}$ SDD tablet formulations. ${ }^{69}$ Therefore, the ARMOR2, part 1 trial was designed to evaluate the safety of escalating doses of galeterone in the SDD tablet formulation to determine the recommended dose for the Phase II ARMOR2, part 2 and Phase III (ARMOR3-SV) trials.

In ARMOR1 and ARMOR2 part 1, 12/49 and 6/28 patients discontinued galeterone therapy before 12 weeks due to treatment-related adverse events (AEs). In these trials, 21 and 19 patients were eligible for the expansion phase of ARMOR1 and ARMOR2 part 1, respectively. Overall the treatment was well tolerated in this case and, although most patients in both studies experienced at least one AE, no action was required in most cases. The most common treatment-related AEs were nausea, pruritus, fatigue, anorexia, diarrhea, and increased ALT levels (Table 3). Of note, no apparent mineralocorticoid excess syndrome was observed despite concomitant corticosteroid use not being required. In terms of overall clinical activity across all dose levels, $22 \%$ and $48 \%$ of patients achieved PSA P $_{50}$ in ARMOR 1 and ARMOR2 part 1, respectively. In the $2,550 \mathrm{mg}$ dose cohort of ARMOR2 part 1,72.7\% and 54.5\% achieved a PSA decline $\geq 30 \%$ and $\geq 50 \%$, respectively. The pharmacokinetic results of this study demonstrated that there was no increase in plasma exposure to doses higher than 2,550 mg, which was the recommended dose for subsequent Phase II and Phase III trials based on pharmacokinetics, safety, and PSA response data. ${ }^{69}$

ARMOR2 part 2 is an ongoing study designed to assess the safety and efficacy of the 2,550 $\mathrm{mg}$ SDD tablet formulation of galeterone once a day in four distinct $\mathrm{mCRPC}$ cohorts: non-metastatic treatment-naïve (TN) CRPC $\left(\mathrm{M}_{0}-\mathrm{TN}\right.$, 
Table 3 Main adverse events in the ARMORI and ARMOR2 clinical trials

\begin{tabular}{|c|c|c|c|}
\hline & ARMORI ${ }^{69}$ & $\begin{array}{l}\text { ARMOR2, } \\
\text { part } 1^{69}\end{array}$ & $\begin{array}{l}\text { ARMOR2, parts I } \\
\text { and } 2 \text { (combined } \\
\text { study) }\end{array}$ \\
\hline \multicolumn{4}{|l|}{ Main grade I or $2 \mathrm{AEs}^{\mathrm{a}}$} \\
\hline Fatigue & $16(32.7 \%)$ & $9(32.1 \%)$ & 35 (32.7\%) \\
\hline Nausea & $12(24.5 \%)$ & $13(46.4 \%)$ & $36(33.6 \%)$ \\
\hline Vomiting & $6(12.2 \%)$ & $8(28.6 \%)$ & $13(12.1 \%)$ \\
\hline Diarrhea & II (22.4\%) & $4(14.3 \%)$ & 17 (I5.9\%) \\
\hline Decreased appetite & $6(12.2 \%)$ & $6(21.4 \%)$ & $22(20.6 \%)$ \\
\hline Pruritus & II (22.4\%) & $9(32.1 \%)$ & 28 (26.2\%) \\
\hline Increased AST level & $13(26.5 \%)$ & I (3.6\%) & $9(8.4 \%)$ \\
\hline \multicolumn{4}{|l|}{ All grade $\geq 3 \mathrm{AEs}^{\mathrm{b}}$} \\
\hline Increased ALT level & $8(16.3 \%)$ & $3(10.7 \%)$ & $5(4.7 \%)$ \\
\hline Increased AST level & $3(6.1 \%)$ & I (3.6\%) & $2(1.9 \%)$ \\
\hline Increased bilirubin & I (2\%) & 0 & $\mathrm{I}(<\mathrm{I} \%)$ \\
\hline Constipation & 0 & I (3.6\%) & 0 \\
\hline Diarrhea & 0 & I (3.6\%) & $\mathrm{I}(<\mathrm{I} \%)$ \\
\hline Fatigue & I (2\%) & 0 & $3(2.8 \%)$ \\
\hline Rash & 0 & I (3.6\%) & $\mathrm{I}(<\mathrm{I} \%)$ \\
\hline Pruritus & 0 & 0 & $4(3.7 \%)$ \\
\hline Hypokalemia & NR & NR & $3(2.8 \%)$ \\
\hline Hypertension & NR & NR & $2(1.9 \%)$ \\
\hline
\end{tabular}

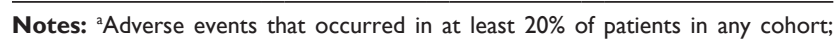
bgrade $\geq 3$ adverse events that occurred in $>1 \%$ of patients in any cohort.

Abbreviations: AEs, adverse events; NR, not reported; ALT, alanine aminotransferase; AST, aspartate aminotransferase.

seven patients), metastatic TN CRPC ( $\mathrm{M}_{1}-\mathrm{TN}, 24$ patients), abiraterone-refractory mCRPC (eleven patients), and enzalutamide-refractory mCRPC (two patients). ${ }^{70}$ Preliminary results of the first three patient cohorts were presented at the 2014 American Society of Clinical Oncology (ASCO) Annual Meeting and demonstrated significant clinical activity with PSA declines of $\geq 30 \%$ and $\geq 50 \%$ in $83 \%$ and $67 \%$ in the $\mathrm{M}_{0}$-TN group, and $92 \%$ and $83 \%$ in the $\mathrm{M}_{1}-\mathrm{TN}$ cohort, respectively. Two out of five (40\%) patients in the abiraterone-refractory cohort achieved a PSA decline $\geq 30 \%$. In terms of toxicity, $94 \%$ of all AEs were grade 1 or 2 and the most common events were nausea, diarrhea, fatigue, and pruritus. No mineralocorticoid excess symptoms or seizures were recorded in the study. ${ }^{70}$ These results were updated at the 2014 European Society of Medical Oncology (ESMO) meeting, with safety data of the 107 patients included and efficacy results demonstrating a PSA decline $\geq 30 \%$ and $\geq 50 \%$ in $83 \%$ and $70 \%$ of patients in the $\mathrm{M}_{0}$ and $\mathrm{M}_{1} \mathrm{TN}$ cohorts, respectively (Table 4). In the abiraterone-refractory cohort, among the 15 evaluable patients to date, $13 \%$ achieved a PSA decline $\geq 30 \%$ and $27 \%$ had some degree of PSA decline. ${ }^{71}$

In an exploratory analysis of circulating tumor cells in patients included in the ARMOR2 trial, 90\% (64/71) of enrolled patients had $\geq 1$ CTC detected. ${ }^{71}$ In the $\mathrm{M}_{0}$ and $\mathrm{M}_{1}$
Table 4 ARMOR2: galeterone efficacy summary

\begin{tabular}{|c|c|c|c|}
\hline Cohort & $\begin{array}{l}\text { Number } \\
\text { of patients }\end{array}$ & $\begin{array}{l}\text { Any PSA } \\
\text { decline }\end{array}$ & $\begin{array}{l}\text { Best response by } \\
\text { PCWG2 }\end{array}$ \\
\hline $\begin{array}{l}\text { Non-metastatic } \\
\left(M_{0}-T N\right) \text { mCRPC }\end{array}$ & 21 & $21(100 \%)$ & $\begin{array}{l}\text { No evidence of } \\
\text { metastasis at } 12 \text { weeks }\end{array}$ \\
\hline $\begin{array}{l}\text { Metastatic } \\
\left(M_{1}-T N\right) \text { mCRPC }\end{array}$ & 39 & $35(90 \%)$ & Stable disease: $75 \%$ \\
\hline Abi-R mCRPC & 30 & II (37\%) & Stable disease: $47 \%$ \\
\hline Enz-R mCRPC & 9 & 4 (44\%) & Stable disease: $57 \%$ \\
\hline
\end{tabular}

Note: Data from Taplin et al. ${ }^{70}$

Abbreviations: $m C R P C$, metastatic castration-resistant prostate cancer; TN, treatment-naïve; Abi-R, abiraterone refractory; Enz-R, enzalutamide refractory; PCWG2, Prostate Cancer Working Group 2; PSA, prostate specific antigen.

cohorts, the C-terminal AR immunohistochemical assay using the Epic Sciences platform was performed and seven of these patients were found to have AR C-terminal loss, implying the presence of AR splice variants (perhaps including AR-V7 as well as others). Notably, six of these seven patients (86\%) with C-terminal loss achieved a PSA $_{50}$, suggesting that galeterone may be active in patients harboring AR splice variants (eg, AR-V7). Four patients continued on galeterone in the optional extension phase, with time on treatment ranging from 155 to $>334$ days. Another interesting finding suggests that post-galeterone therapies with docetaxel or other AR-directed therapies (such as abiraterone and enzalutamide) may confer PSA declines, although this retrospective analysis included only nine patients, five of whom had discontinued galeterone due to AEs. ${ }^{72}$

Based on the promising clinical results from the Phase II galeterone program, a registrational Phase III trial was recently launched (Figure 2; ARMOR3-SV, NCT02438007). ${ }^{73}$ To this end, ARMOR3-SV is a 148-patient randomized study in men with $\mathrm{M}_{1} \mathrm{CRPC}$ who have not previously received abiraterone, enzalutamide or taxane chemotherapy (except docetaxel for hormone-sensitive metastatic prostate cancer). This trial has achieved a notable "first", in that it is the first pivotal trial in prostate cancer to base its enrollment on a biomarker: in this case, AR-V7. Patients who appear eligible for this trial are pre-screened for AR-V7 using a CTC-based RT-PCR assay developed by Qiagen and performed by LabCorp in a Clinical Laboratory Improvement Amendments-certified environment. The prevalence of CTC-positive AR-V7-positive patients in this setting is expected to be $8 \%-12 \%$ (about ten patients will have to be screened to identify one AR-V7-positive case). Subsequently, only AR-V7-positive men are allowed to proceed to formal randomization, and these patients are allocated equally to receive enzalutamide $160 \mathrm{mg}$ daily or galeterone $2,550 \mathrm{mg}$ daily (Figure 2). Patients are removed from study only if they 


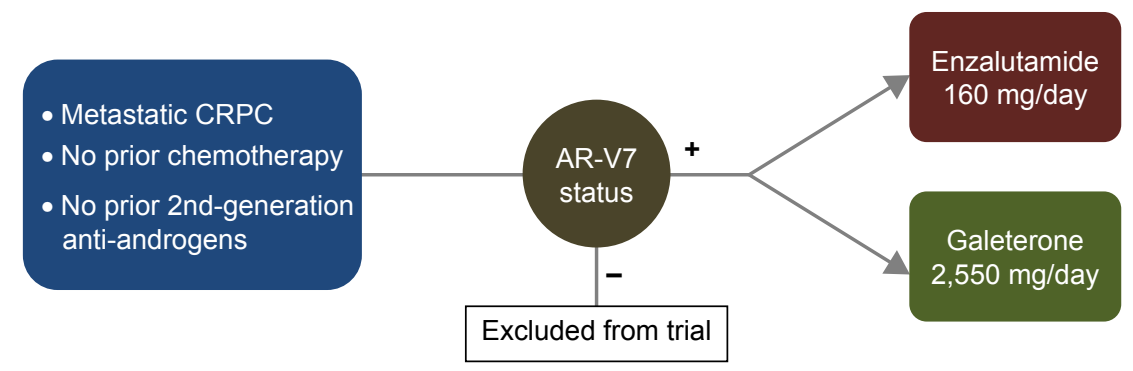

\section{Planned accrual: 148 patients}

\section{Primary endpoint:}

Radiographic progression-free survival

\section{Secondary endpoints:}

Overall survival

Time to cytotoxic therapy

Figure 2 ARMOR3-SV: Phase III randomized trial design and study endpoints.

Note: Data from Taplin et al. ${ }^{73}$

Abbreviations: CRPC, castration-resistant prostate cancer; AR-V7, androgen receptor splice variant 7.

develop confirmed radiographic progression of their disease (according to Prostate Cancer Working Group 2 criteria), or if they develop unmanageable toxicity. The primary endpoint of ARMOR3-SV is rPFS, with OS being the key secondary endpoint. Enrollment is expected to finish in early 2017, and primary results on the rPFS endpoint are expected by late 2017. If successful, this trial would be the first study to result in drug approval using an rPFS endpoint, and the first trial to employ a biomarker-selection design in prostate cancer. Moreover, if this trial demonstrates a superiority of galeterone over enzalutamide, it could represent a new option for patients with disease progression after available therapies who develop AR-V7 positive CTCs during the course of their disease.

\section{Perspectives}

Despite the many advances achieved thus far in the understanding of the biology of $\mathrm{mCRPC}$, it is clear that with more active AR-directed drugs the complexity of the mechanisms of resistance and progression is increasing, and novel approaches are needed to improve patient outcomes. Galeterone is a unique AR-directed drug with multiple mechanisms of action including CYP17 inhibition while also acting as an AR antagonist and AR degrader. Therefore, galeterone could potentially overcome aberrant AR signaling mediated by mutant-activated AR as well as constitutively-active AR splice variants, which have been recognized as potential escape mechanisms to abiraterone and enzalutamide, by virtue of its protein degradation mechanism. It should be highlighted that galeterone will not address the non-AR-dependent mechanisms of castrationresistance.

In order to evaluate galeterone's efficacy for AR-V7 positive patients, the first biomarker-driven Phase III randomized trial in mCRPC (Figure 2; ARMOR3-SV, NCT02438007) has been launched and will compare the efficacy of galeterone against enzalutamide in $\mathrm{mCRPC}$ patients harboring AR-V7, and hopefully will demonstrate activity in this refractory patient population. Meanwhile, additional Phase II trials are being planned using galeterone in the post-abiraterone and post-enzalutamide populations. Finally, if galeterone is truly capable of targeting and degrading AR-V7 and other splice variants, it remains possible that this agent may theoretically sensitize (or even re-sensitize) CRPC patients to treatment with abiraterone and enzalutamide, although this hypothesis remains to be tested.

\section{Acknowledgment}

ESA has received funding from the Prostate Cancer Foundation, the Patrick C. Walsh Fund, and NIH grants R01 CA185297 and P30 CA006973.

\section{Disclosure}

ESA has served as a paid consultant/advisor for Janssen, Astellas, Sanofi, Dendreon, Merck, Essa, and Medivation; has received research funding to his institution from Janssen, Johnson \& Johnson, Medivation, Sanofi, Dendreon, Bristol Myers Squibb, Genentech, Novartis, Bayer and Tokai; and is a co-inventor of a biomarker technology that has been licensed to Tokai. DAB declares no conflicts of interest in this work.

\section{References}

1. Torre LA, Bray F, Siegel RL, Ferlay J, Lortet-Tieulent J, Jemal A. Global cancer statistics, 2012. CA Cancer J Clin. 2015;65(2):87-108.

2. Siegel RL, Miller KD, Jemal A. Cancer statistics, 2016. CA Cancer J Clin. 2016;66(1):7-30.

3. Balk SP. Androgen receptor as a target in androgen-independent prostate cancer. Urology. 2002;60(3 Suppl 1):132-138; discussion 138-139. 
4. Scher HI, Sawyers CL. Biology of progressive, castration-resistant prostate cancer: directed therapies targeting the androgen-receptor signaling axis. J Clin Oncol. 2005;23(32):8253-8261.

5. Ryan CJ, Tindall DJ. Androgen receptor rediscovered: the new biology and targeting the androgen receptor therapeutically. J Clin Oncol. 2011; 29(27):3651-3658.

6. Kluetz PG, Ning YM, Maher VE, et al. Abiraterone acetate in combination with prednisone for the treatment of patients with metastatic castration-resistant prostate cancer: U.S. Food and Drug Administration drug approval summary. Clin Cancer Res. 2013;19(24):6650-6656.

7. Ning YM, Brave M, Maher VE, et al. U.S. Food and Drug Administration Approval Summary: Enzalutamide for the Treatment of Patients With Chemotherapy-Naive Metastatic Castration-Resistant Prostate Cancer. Oncologist. 2015;20(8):960-966.

8. de Bono JS, Logothetis CJ, Molina A, et al. Abiraterone and increased survival in metastatic prostate cancer. $N$ Engl J Med. 2011;364(21): 1995-2005

9. Ryan CJ, Smith MR, de Bono JS, et al. Abiraterone in metastatic prostate cancer without previous chemotherapy. $N$ Engl J Med. 2013;368(2): $138-148$.

10. Scher HI, Fizazi K, Saad F, et al. Increased survival with enzalutamide in prostate cancer after chemotherapy. $N$ Engl J Med. 2012;367(13): $1187-1197$.

11. Beer TM, Armstrong AJ, Rathkopf DE, et al. Enzalutamide in metastatic prostate cancer before chemotherapy. $N$ Engl J Med. 2014;371(5): $424-433$.

12. Efstathiou E, Titus M, Tsavachidou D, et al. Effects of abiraterone acetate on androgen signaling in castrate-resistant prostate cancer in bone. J Clin Oncol. 2012;30(6):637-643.

13. Efstathiou E, Titus M, Wen S, et al. Molecular characterization of enzalutamide-treated bone metastatic castration-resistant prostate cancer. Eur Urol. 2015;67(1):53-60.

14. Carreira S, Romanel A, Goodall J, et al. Tumor clone dynamics in lethal prostate cancer. Sci Transl Med. 2014;6(254):254ra125.

15. Joseph JD, Lu N, Qian J, et al. A clinically relevant androgen receptor mutation confers resistance to second-generation antiandrogens enzalutamide and ARN-509. Cancer Dis. 2013;3(9):1020-1029.

16. Azad AA, Volik SV, Wyatt AW, et al. Androgen Receptor Gene Aberrations in Circulating Cell-Free DNA: Biomarkers of Therapeutic Resistance in Castration-Resistant Prostate Cancer. Clin Cancer Res. 2015;21(10):2315-2324.

17. Nakazawa M, Antonarakis ES, Luo J. Androgen receptor splice variants in the era of enzalutamide and abiraterone. Horm Cancer. 2014;5(5): 265-273.

18. Antonarakis ES, Lu C, Wang H, et al. AR-V7 and resistance to enzalutamide and abiraterone in prostate cancer. $N$ Engl J Med. 2014;371(11): $1028-1038$.

19. Arora VK, Schenkein E, Murali R, et al. Glucocorticoid receptor confers resistance to antiandrogens by bypassing androgen receptor blockade. Cell. 2013;155(6):1309-1322.

20. Silberstein JL, Taylor MN, Antonarakis ES. Novel Insights into Molecular Indicators of Response and Resistance to Modern Androgen-Axis Therapies in Prostate Cancer. Curr Urol Rep. 2016;17(4):29.

21. Maughan BL, Antonarakis ES. Clinical Relevance of Androgen Receptor Splice Variants in Castration-Resistant Prostate Cancer. Curr Treat Options Oncol. 2015;16(12):57.

22. de Bono JS, Oudard S, Ozguroglu M, et al. Prednisone plus cabazitaxel or mitoxantrone for metastatic castration-resistant prostate cancer progressing after docetaxel treatment: a randomised open-label trial. Lancet. 2010;376(9747):1147-1154.

23. Tannock IF, de Wit R, Berry WR, et al. Docetaxel plus prednisone or mitoxantrone plus prednisone for advanced prostate cancer. $N$ Engl $J$ Med. 2004;351(15):1502-1512.

24. Logothetis CJ, Basch E, Molina A, et al. Effect of abiraterone acetate and prednisone compared with placebo and prednisone on pain control and skeletal-related events in patients with metastatic castration-resistant prostate cancer: exploratory analysis of data from the COU-AA-301 randomised trial. Lancet Oncol. 2012;13(12):1210-1217.
25. Ryan CJ, Smith MR, Fizazi K, et al. Abiraterone acetate plus prednisone versus placebo plus prednisone in chemotherapy-naive men with metastatic castration-resistant prostate cancer (COU-AA-302): final overall survival analysis of a randomised, double-blind, placebo-controlled phase 3 study. Lancet Oncol. 2015;16(2):152-160.

26. Kantoff PW, Higano CS, Shore ND, et al. Sipuleucel-T immunotherapy for castration-resistant prostate cancer. $N$ Engl J Med. 2010;363(5): 411-422.

27. Parker C, Nilsson S, Heinrich D, et al. Alpha emitter radium-223 and survival in metastatic prostate cancer. $N$ Engl J Med. 2013;369(3): 213-223.

28. Basch E, Loblaw DA, Oliver TK, et al. Systemic therapy in men with metastatic castration-resistant prostate cancer: American Society of Clinical Oncology and Cancer Care Ontario clinical practice guideline. J Clin Oncol. 2014;32(30):3436-3448.

29. Gillessen S, Omlin A, Attard G, et al. Management of patients with advanced prostate cancer: recommendations of the St Gallen Advanced Prostate Cancer Consensus Conference (APCCC) 2015. Ann Oncol. 2015;26(8):1589-1604.

30. Lorente D, Mateo J, Perez-Lopez R, de Bono JS, Attard G. Sequencing of agents in castration-resistant prostate cancer. Lancet Oncol. 2015; 16(6):e279-e292.

31. Watson PA, Arora VK, Sawyers CL. Emerging mechanisms of resistance to androgen receptor inhibitors in prostate cancer. Nat Rev Cancer. 2015;15(12):701-711.

32. Efstathiou E, Titus M, Wen S, et al. Enzalutamide (ENZA) in combination with abiraterone acetate (AA) in bone metastatic castration resistant prostate cancer (mCRPC). J Clin Oncol. 2014;32:5s (suppl; abstr 5000).

33. Robinson D, Van Allen EM, Wu YM, et al. Integrative clinical genomics of advanced prostate cancer. Cell. 2015;161(5):1215-1228.

34. Yu Z, Chen S, Sowalsky AG, et al. Rapid induction of androgen receptor splice variants by androgen deprivation in prostate cancer. Clin Cancer Res. 2014;20(6):1590-1600.

35. Scher HI, Lu D, Schreiber NA, et al. Association of AR-V7 on circulating tumor cells as a treatment-specific biomarker with outcomes and survival in castration-resistant prostate cancer. JAMA Oncol. Epub 2016 Jun 4.

36. Sprenger C, Uo T, Plymate S. Androgen receptor splice variant V7 (AR-V7) in circulating tumor cells: a coming of age for AR splice variants? Ann Oncol. 2015;26(9):1805-1807.

37. Antonarakis ES, Lu C, Luber B, et al. Androgen Receptor Splice Variant 7 and Efficacy of Taxane Chemotherapy in Patients With Metastatic Castration-Resistant Prostate Cancer. JAMA Oncol. 2015;1(5):582-591.

38. Onstenk W, Sieuwerts AM, Kraan J, et al. Efficacy of Cabazitaxel in Castration-resistant Prostate Cancer Is Independent of the Presence of AR-V7 in Circulating Tumor Cells. Eur Urol. 2015;68(6):939-945.

39. Nakazawa M, Lu C, Chen Y, et al. Serial blood-based analysis of AR-V7 in men with advanced prostate cancer. Ann Oncol. 2015;26(9): 1859-1865.

40. Smith MR, Antonarakis ES, Ryan CJ, et al. Phase 2 Study of the Safety and Antitumor Activity of Apalutamide (ARN-509), a Potent Androgen Receptor Antagonist, in the High-risk Nonmetastatic Castrationresistant Prostate Cancer Cohort. Eur Urol. Epub 2016 May 6.

41. Romanel A, Gasi Tandefelt D, Conteduca V, et al. Plasma AR and abiraterone-resistant prostate cancer. Sci Transl Med. 2015;7(312): 312re310.

42. Wyatt AW, Azad AA, Volik SV, et al. Genomic Alterations in Cell-Free DNA and Enzalutamide Resistance in Castration-Resistant Prostate Cancer. JAMA Oncol. Epub 2016 May 5.

43. Beltran H, Tomlins S, Aparicio A, et al. Aggressive variants of castration-resistant prostate cancer. Clin Cancer Res. 2014;20(11): 2846-2850.

44. Small EJ, Huang J, Youngren J, et al. Characterization of neuroendocrine prostate cancer (NEPC) in patients with metastatic castration resistant prostate cancer (mCRPC) resistant to abiraterone (Abi) or enzalutamide (Enz): Preliminary results from the SU2C/PCF/AACR West Coast Prostate Cancer Dream Team (WCDT). J Clin Oncol. 2015;33 (suppl; abstr 5003). 
45. Beltran H, Jendrisak A, Landers M, et al. The Initial Detection and Partial Characterization of Circulating Tumor Cells in Neuroendocrine Prostate Cancer. Clin Cancer Res. 2016;22(6):1510-1519.

46. Boudadi K, Antonarakis ES. Resistance to Novel Antiandrogen Therapies in Metastatic Castration-Resistant Prostate Cancer. Clin Med Insights Oncol. 2016;10(Suppl 1):1-9.

47. Beltran H, Prandi D, Mosquera JM, et al. Divergent clonal evolution of castration-resistant neuroendocrine prostate cancer. Nat Med. 2016; 22(3):298-305.

48. Aparicio AM, Shen L, Tapia EL, et al. Combined Tumor Suppressor Defects Characterize Clinically Defined Aggressive Variant Prostate Cancers. Clin Cancer Res. 2016;22(6):1520-1530.

49. Njar VC, Kato K, Nnane IP, Grigoryev DN, Long BJ, Brodie AM. Novel 17-azolyl steroids, potent inhibitors of human cytochrome 17 alpha-hydroxylase-C17,20-lyase (P450(17) alpha): potential agents for the treatment of prostate cancer. J Med Chem. 1998;41(6):902-912.

50. Handratta VD, Vasaitis TS, Njar VC, et al. Novel C-17-heteroaryl steroidal CYP17 inhibitors/antiandrogens: synthesis, in vitro biological activity, pharmacokinetics, and antitumor activity in the LAPC4 human prostate cancer xenograft model. J Med Chem. 2005; 48(8):2972-2984.

51. Vasaitis T, Belosay A, Schayowitz A, et al. Androgen receptor inactivation contributes to antitumor efficacy of 17 \{alpha $\}$-hydroxylase/17,20-lyase inhibitor 3beta-hydroxy-17-(1H-benzimidazole-1-yl)androsta-5,16diene in prostate cancer. Mol Cancer Ther. 2008;7(8):2348-2357.

52. Purushottamachar P, Godbole AM, Gediya LK, et al. Systematic structure modifications of multitarget prostate cancer drug candidate galeterone to produce novel androgen receptor down-regulating agents as an approach to treatment of advanced prostate cancer. J Med Chem. 2013;56(12):4880-4898.

53. Soifer HS, Souleimanian N, Wu S, et al. Direct regulation of androgen receptor activity by potent CYP17 inhibitors in prostate cancer cells. J Biol Chem. 2012;287(6):3777-3787.

54. Yu Z, Cai C, Gao S, Simon NI, Shen HC, Balk SP. Galeterone prevents androgen receptor binding to chromatin and enhances degradation of mutant androgen receptor. Clin Cancer Res. 2014;20(15):4075-4085.

55. Al Nakouzi N, Wang C, Jacoby D, Gleave ME, Zoubeidi A. Galeterone suppresses castration-resistant and enzalutamide-resistant prostate cancer growth in vitro. Mol Cancer Ther. 2013;12(11 Suppl):C89.

56. Njar VC, Brodie AM. Discovery and development of Galeterone (TOK-001 or VN/124-1) for the treatment of all stages of prostate cancer. J Med Chem. 2015;58(5):2077-2087.

57. Li B, Lu W, Chen Z. Regulation of Androgen Receptor by E3 Ubiquitin Ligases: for More or Less. Receptors Clin Investig. 2014;1(5):1-10.

58. Qi J, Fan L, Hussain A. Implications of ubiquitin ligases in castrationresistant prostate cancer. Curr Opin Oncol. 2015;27(3):172-176.

59. Lin HK, Wang L, Hu YC, Altuwaijri S, Chang C. Phosphorylationdependent ubiquitylation and degradation of androgen receptor by Akt require Mdm2 E3 ligase. EMBO J. 2002;21(15):4037-4048.

60. Riley MF, Lozano G. The Many Faces of MDM2 Binding Partners. Genes Cancer. 2012;3(3-4):226-239.
61. Murata S, Minami Y, Minami M, Chiba T, Tanaka K. CHIP is a chaperone-dependent E3 ligase that ubiquitylates unfolded protein. EMBO Rep. 2001;2(12):1133-1138.

62. Li B, Lu W, Yang Q, Yu X, Matusik RJ, Chen Z. Skp2 regulates androgen receptor through ubiquitin-mediated degradation independent of Akt/ mTOR pathways in prostate cancer. Prostate. 2014;74(4):421-432.

63. Qi J, Tripathi M, Mishra R, et al. The E3 ubiquitin ligase Siah2 contributes to castration-resistant prostate cancer by regulation of androgen receptor transcriptional activity. Cancer Cell. 2013;23(3):332-346.

64. Xu K, Shimelis H, Linn DE, et al. Regulation of androgen receptor transcriptional activity and specificity by RNF6-induced ubiquitination. Cancer Cell. 2009;15(4):270-282.

65. Burska UL, Harle VJ, Coffey K, et al. Deubiquitinating enzyme Usp12 is a novel co-activator of the androgen receptor. J Biol Chem. 2013; 288(45):32641-32650.

66. McClurg UL, Summerscales EE, Harle VJ, Gaughan L, Robson CN. Deubiquitinating enzyme Usp12 regulates the interaction between the androgen receptor and the Akt pathway. Oncotarget. 2014;5(16): 7081-7092.

67. Kwegyir-Afful AK, Ramalingam S, PurushottamacharP, Ramamurthy VP, Njar VC. Galeterone and VNPT55 induce proteasomal degradation of AR/AR-V7, induce significant apoptosis via cytochrome c release and suppress growth of castration resistant prostate cancer xenografts in vivo. Oncotarget. 2015;6(29):27440-27460.

68. Dransfield DT, Namdev N, Jacoby DB, Ferrante K. Galeterone-induced degradation of the androgen receptor involves inhibition of deubiquitinating enzymes. In: AACR Annual Meeting; New Orleans, April 18, 2016; Abstract 1234. 2016.

69. Montgomery B, Eisenberger MA, Rettig MB, et al. Androgen Receptor Modulation Optimized for Response (ARMOR) Phase I and II Studies: Galeterone for the Treatment of Castration-Resistant Prostate Cancer. Clin Cancer Res. 2016;22(6):1356-1363.

70. Montgomery B, Eisenberger MA, Heath EI, et al. Galeterone in men with CRPC: Results in four distinct patient populations from the ARMOR2 study. J Clin Oncol. 2014;32:5s (supp1; abstr 5029).

71. Taplin ME, Chi KN, Chu F, et al. Activity of galeterone in castrateresistant prostate cancer (CRPC) with C-terminal AR loss: Results from ARMOR2. European Journal of Cancer. 2014;50(6):8.

72. McKay RR, Werner L, Fiorillo M, et al. Activity of sequential therapies (txs) in patients (pts) with castration resistant prostate cancer (CRPC) previously treated with galeterone. J Clin Oncol. 2015;33 (suppl; abstr e16072).

73. Taplin ME, Antonarakis ES, Dransfield DT, Ferrante KJ, De Bono JS. Androgen receptor modulation optimized for response: Splice variant (ARMOR3-SV)-Randomized, open-label, multicenter, controlled study of galeterone vs enzalutamide in men with metastatic castration-resistant prostate cancer (mCRPC) expressing AR-V7 splice variant. J Clin Oncol. 2015;33 (suppl; abstr TPS5069).

\section{Publish your work in this journal}

Drug Design, Development and Therapy is an international, peerreviewed open-access journal that spans the spectrum of drug design and development through to clinical applications. Clinical outcomes, patient safety, and programs for the development and effective, safe, and sustained use of medicines are a feature of the journal, which

\section{Dovepress}

has also been accepted for indexing on PubMed Central. The manuscript management system is completely online and includes a very quick and fair peer-review system, which is all easy to use. Visit http://www.dovepress.com/testimonials.php to read real quotes from published authors. 